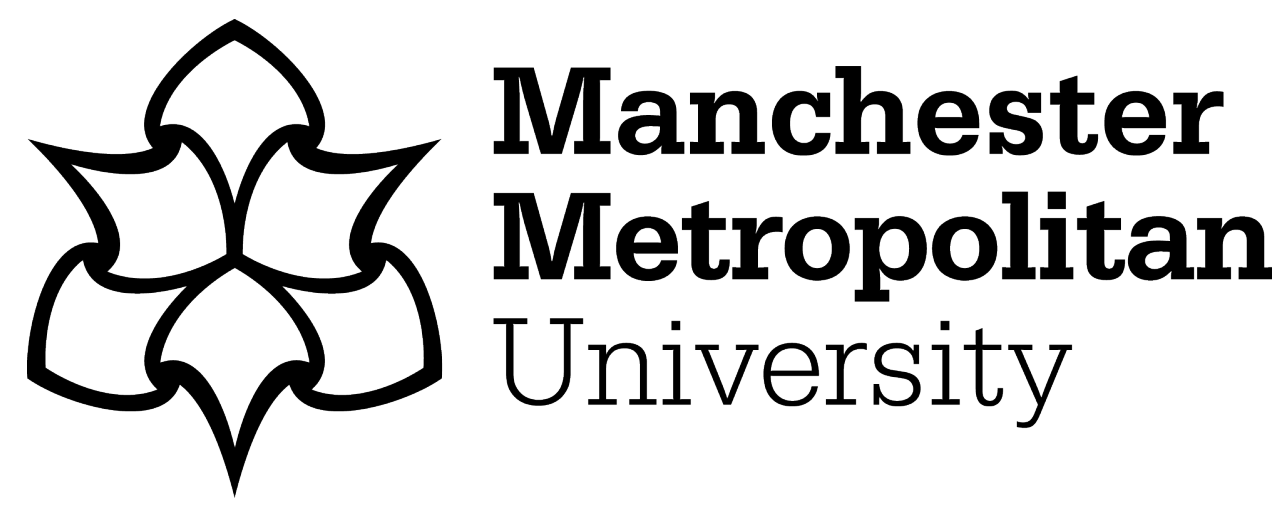

Townsend, Katherine and Niedderer, Kristina ORCID logoORCID: https://orcid.org/0000-0002-8188-6338 (2021) Craft as a meeting place. Craft Research, 12 (1). pp. 3-8. ISSN 2040-4689

Downloaded from: https://e-space.mmu.ac.uk/627865/

Version: Accepted Version

Publisher: Intellect

DOI: https://doi.org/10.1386/crre_00037_2

Please cite the published version 


\title{
EDITORIAL
}

\author{
KATHERINE TOWNSEND \\ Nottingham Trent University, UK
}

KRISTINA NIEDDERER

Manchester Metropolitan University, UK

\section{Craft as a meeting place}

Throughout 2020, individuals and groups of makers have continued to learn and practice their craft; physically together where possible, and via online platforms where the sharing of skill and companionship has been a necessity and lifeline during the coronavirus pandemic.

While craft is often a singular endeavour, generally the learning and teaching of creative practice is undertaken in small groups or one-to-one, based on the exchange of explicit and, significantly, embodied 'tacit' knowledge because "we know more than we can tell" (Polyani, 1966: 4, cited in Harris, 2020). Tacit knowledge and skills are acquired through observation, imitation, and practice which teach the body to respond intentionally and intuitively to materials, situations and people (Ibid.).

The shift to working from home brought about by the coronavirus pandemic has highlighted the transactional nature of work and the fundamental human need for daily social interaction to make working (and making work) meaningful (Haningan, 2020). Restrictions preventing people to meet or undertake activities in groups, have closed down the positive 'transactional space' offered by craft and its beneficial impact on mental health and in turn, everyday activities (Horghagen, Fostvedt and Alsaker, 2014). This has been felt particularly by educators in practical subjects, such as craft and design, who have had to expediently translate showing and telling experiences into step-by-step, online exercises that students can follow and successfully implement in varying domestic environments during the pandemic induced closures of university workshops. 
The loss of space to work in, the availability of raw materials and machinery and, crucially, of having someone next to you while you practice (and practise) has cut out a significant, serendipitous part of thinking and making. The translation of physical gestural knowledge through analogue-digital material practice (Nimkulrat, 2020) has been reversed, with digitalanalogue, post-digital (and post-human) systems taking priority. While 'meeting' online has become essential for work and leisure, craft has come into its own as a process and methodology for negotiating unfamiliar territories and technologies. It is for this reason that we focus on the importance of craft as a meeting place in this issue.

Marte Sørebø Gulliksen's autobiographical Portrait, There and back again, reiterates connections between sustained physical engagement and cognitive function, through an autoethnographic narrative enquiry into how, as a woodcarver, she experienced the illnessinduced loss of her sense of space and of her ability to ideate and rotate three-dimensional forms. Theoretically positioned in the field of embodied cognition, Gulliksen recounts how her experience of a brain tumour required her to recalibrate and ultimately re-evaluate the physical and mental making space through the crafting of the Purkinje Series of wooden artefacts. Inspired by visual representations of Purkinje cells found in the cerebellum, the part of the brain responsible for coordinating voluntary movements and motor skills, these complex 'bowl' forms reflect the mastery of material, body and mind, as featured on the cover of this issue.

Gulliksen makes the case for the development of craft skills being even more important in the future as we increasingly navigate a virtual world and our everyday lives provide limited physical interaction, presenting us with a 'task performance deficit' (Goodman et al. 2016). Embodied learning through 'making matters' and there is evidence that engagement with actual materials stimulates neural networks facilitating our abstract thinking (Gulliksen 2017).

Hinda Mandell reflects on the communal aspect of meeting through craft, by describing how a yarn installation designed to enhance a neglected park in Rochester, New York attracted positive feedback from the community, but a negative reaction from the local council. Mandell explores how craft activism is organized, the motivations of the makers involved, how they collaborate to beautify their surroundings, but how such action can be misunderstood as subversive and even 'monstrous' (Moffat, 2019). The author uses the term 
'textile togetherness' to explain the yarn-based making process and supports the important role of 'civic crafts', a term used by Otto von Busch (2017) who states:

Craft capabilities can be a way to celebrate togetherness - not as a political contest of wills, but as a creative way to test out how we can all contribute to the public environment and to civic life. Making together, and using the neutral space of the park bench as a material as well as a social jig, speak of a shared public good.

The article offers suggestions for future organizers of yarn installations and calls for more public art to be placed in urban areas as outcomes of community engagement.

In a related vein, Kirsi Niinimaki, Marium Durrani and Cindy Kohtala discuss 'Emerging DIY Activities to Enable Well-being and Connected Societies', by interviewing the organizers and examining the activities of six DIY textile and clothing groups based in Helsinki. The research focuses on communities Doing It Together (DIT) and Doing It With Others (DIWO) and how activities such as handling and repairing one's own clothing influences well-being at individual, community and societal levels by activating sustainability-oriented values. The overall craft teaching philosophy of all of the groups is to foster a non-hierarchical learning making space, which empowers the amateur through the psychological benefits of making (Hackney, 2013; Collier and Wayment, 2017).

The theme of craft as a community practice where individuals share craft skills and learn from each other is explored hands-on by Linda Warner, Pirita Seitamaa-Hakkarainen and Kai Hakkarainen. Working with two quilting communities in Aotearoa, New Zealand, the authors have sought a deeper understanding of informal learning and teaching practices in these communities. Taking a sociocultural perspective, the authors have identified and discussed the socially interactive and multimodal nature of making where thinking through hands and minds intersects seamlessly in the makers embodied experiences and interactions.

Gaitri Kumari and Abhaya Ranjan Srivastava investigate the traditional practice of Paitker painting in Jharkhand, India, with regard to the preservation of this heritage practice, illustrated by Bijoy Chitrakar depicting "daily life of local community" as the Remarkable Image. Exploring its history and current socio-economic situation, the authors explore the role and efforts of the state in saving this heritage practice. Their study reveals that besides 
the need to promote an interest in learning the skill, creating favorable economic conditions, through increasingly digitally networked means is crucial. The study also shows that this is not easy and requires skills of another kind, which have to be learned or they can make heritage craft practitioners dependent on various agents.

In a similar vein, the book on 'The Politics of Vietnamese Craft: American Diplomacy and Domestication' by Jennifer Way (2020), reviewed by Andrea Peach, revisits the American Cold War from a new perspective, focusing on the US craft trade in Vietnam. The author argues that the American government attempted to use the commodification of Vietnamese craft to gain diplomatic support in South Vietnam in the years leading up to the war and highlights the issues that arise when government ideologies are superimposed on craft culture and its development.

With his review of the online symposium 'Blame the Tools', David Durling reports on the role of tools in the craft process, and reflects on the creativity, which craft makers bring to bear in appropriating the new digital medium to their ends. The organizers sought not only to bring together the community but also use the medium to enable a sharing of the creative process.

In the Craft and Industry Report, Hadrian Cook and Kathy Strearn evidences how craft is a meeting place for past and ongoing traditions of making through their research into the rural crafts of South Wiltshire. The study considers contemporary rural crafts and their historical precedents through literature, contact with networks of crafters, interviews with individuals, and a focus on a rural craft event located at the Harnham Water Meadows at Salisbury, a historic location. The ethos of environmental sustainability emerges strongly, through the of sourcing materials and the processes employed, especially for individuals working with wood and thatch. The report establishes that, while few participants sustain themselves financially through their practice, it is clear that participation is value and capability driven. Such an approach emphasizes the agency of craft and its capacity to enhance well-being beyond economic advantage by building bridges to, and with others (von Busch, 2017).

\section{Acknowledgements}


We are delighted to present Volume 12.1 of Craft Research. As always, many people have been involved in the realization of this issue. We wish to thank all our contributors, and those authors whose submissions we regrettably had to turn away. Our gratitude also extends to all our advisors and to our reviewers for their excellent work. Their constructive advice and feedback to authors is an essential part in fulfilling the developmental role of the journal and in advancing the field. We further wish to thank Intellect Publishers for their amazing and unwavering support for our journal, in particular our new journal's manager, Mareike Wehner, and her team.

\section{References}

Collier, A.F. and Wayment, H.A. (2017), 'Psychological Benefits of the "Maker" or Do-ItYourself Movement in Young Adults: A Pathway Towards Subjective Well-Being', Journal of Happiness Studies, 19:4, pp. 1-23.

Goodman, S. G., Seymour, T. L. and Anderson, B. R. (2016), 'Achieving the performance benefits of hands-on experience when using digital devices. A representational approach', Computers in Human Behavior, Volume 59, June 2016, pp. 58-66.

Gulliksen, M. S. (2017). 'Making matters? Unpacking the role of practical aesthetic making activities in the general education through the theoretical lens of embodied learning.' Cogent Education 4 (1): 1415108.

Hackney, F. (2013), 'Quiet activism and the new amateur: The power of home and hobby crafts', Design and Culture, 5:2, pp. 169-193.

Hanningan, N. (2020) Opinion, The Guardian, 18, August https://www.theguardian.com/commentisfree/2020/aug/18/working-from-home-we-miss-thepersonal-interactions-with-colleagues-that-can-lighten-the-load 
Moffat, N. (2019), ‘Mapping This Book: Here be Monsters', in Jools Gilson and Nicola Moffat (eds.), Textiles, Community and Controversy: The Knitting Map, London, Bloomsbury, p. xiv.

Harris, A. (2020) "We know more than we can tell:" Why embodied knowledge matters, https://adrianharris.org/blog/2019/05/17/we-know-more-than-we-can-tell-why-embodiedknowledge-matters/, Accessed 5 January 2021.

Horghagen, S., Fostvedt, B., and Alsaker, S. (2014) 'Craft activities in groups at meeting places: supporting mental health users' everyday occupations', Scandinavian Journal of Occupational Therapy,21:2, 145-152, DOI: 10.3109/11038128.2013.866691

Polyani, M. (1960) The Tacit Dimension,

Nimkulrat, N. (2020) 'Translational Craft: Handmade and gestural knowledge in analoguedigital material practice', Craft Research, 11:2, pp. 237-260.

von Busch, O., (2017)'Civic Crafts and Plug-In Whittling', American Craft Inquiry, 1:1, accessed at https://craftcouncil.org/post/civic-crafts-and-plug-whittling, Accessed 5 January, 2021.

\section{Contributor details}

Kristina Niedderer (Ph.D., MA [RCA]) is professor of design at Manchester Metropolitan University. Previously, She was originally apprenticed and worked as a goldsmith and silversmith in Germany. She then trained as a designer and design researcher in the United Kingdom. Niedderer's research focuses on the role of design to engender mindful interaction and behaviour change for health and sustainability. She led the European project 'Designing for People with Dementia' (2016-2020, MSCA GA No. 691001) as well as the IDoService project (2020-2022, MSCA GA No. 895620).

Contact: Kristina Niedderer, Manchester School of Art, Faculty of Arts \& Humanities, Manchester Metropolitan University, Oxford Road, Manchester M15 6BH, UK. 
E-mail: k.niedderer@mmu.ac.uk

Web addresses: http://www.niedderer.org

ORCID identifier https://orcid.org/0000-0002-8188-6338

Katherine Townsend (Ph.D) is associate professor of fashion and textile crafts at Nottingham Trent University. She leads the Digital Craft and Embodied Knowledge group in the Fashion and Textile Research Centre. Her current research (and Ph.D. supervision) encompasses emotionally durable design, dress archives and wearables, social and sustainable innovation, including ethnographic work with textile artisan groups in Guatemala, supported by the Global Challenges Research Fund (GCRF 2018/ 2020) and Redesigning PPE in collaboration with NHS and industry partners (AHRC 2021-22) . Katherine led the research projects: Crafting Anatomies (2015/2020), Emotional Fit (2017) and has published in The Design Journal, Textile, Textile Design Research and Practice and Clothing Cultures.

Contact: Katherine Townsend, School of Art and Design, Nottingham Trent University, Burton Street, Nottingham, NG1 4BU, UK.

E-mail: katherine.townsend@ntu.ac.uk

Web addresses: https://www.ntu.ac.uk/staff-profiles/art-design/katherine-townsend E-mail: katherine.townsend@ntu.ac.uk ORCID identifier: https://orcid.org/0000-0003-2212-2511 